\title{
A Study on Adult English Training Modes under the backdrop of Free Trade Areas
}

\author{
Zixin Wang, Xiaoxu Chen* \\ Zhejiang Ocean University, Zhoushan, China \\ *Corresponding Author: Xiaoxu Chen, Zhejiang Ocean University, Zhoushan, China

\begin{abstract}
The founding of Free Trade Areas gives boost to a pool of foreign-invested enterprises setting up in China. Thus, the English is a must for employees if they want to be more competent in the job market so as to carve out a better career. Given the poor performance in cross-cultural communications, inadequate vocational English and daily English expressions of the mainstay of society, all the parties concerned should give high priority to the adult English training. This paper mainly focuses on the adult English training in the two Free Trade Areas in China, namely, Xi'an in Shaanxi Province and Zhoushan in Zhejiang Province to better the present adult English training modes.
\end{abstract}

Keywords: Free Trade Areas Problems, Adult English Training, Effective Solutions

\section{INTRODUCTION}

As the society stands ready to embrace the notion of lifelong learning, adult English training is touted by society and sweeping through market. However, problems existed in this industry may backfire since the improper training modes will put a dent in learners' motivation. This study is developed into 3 parts, consisting of the findings of people's view on adult English training, the status quo and problems of adult English training so as to illustrate the effective ways including customized course setting and coverage, the improvement of teaching modes, and means of Internet-assisted learning as well as applying the brand effect to counter the quality problem to better adult English training.

\section{THE BACKGROUND OF STUDY}

\subsection{Political Background}

"China's Education Modernization 2035" noted that China should establish a modern education system of lifelong learning in a bid to make China a powerhouse in terms of education, human resources and talents in 2035. One of the implementations is to set an overall plan while laying down plans in accordance with the regional differences. In the running-up to education modernization, lifelong study and sustainable development of people are hailed by the whole society, the need of learning society emerges. English, a global lingua franca, is vital to economic development and exchanges across the globe. The 19th National Congress of the Communist Party of China stated that China has pursued reform in a more systematic, holistic, and coordinated way, increasing its breadth and depth. As China is committed to intensify the reform in an all-round way, we should also build an enabling English learning society.

\subsection{Theoretical Background}

Many renowned figures in China featured on the motivation of the learners, of which Wen Qiufang (2001) conducted a research between motivation, concept and strategies and led to a conclusion that there is a stable relationship among them. Dai Weidong (2015) pointed out that from learners' perspectives the motivational strategies are effective.

There are some researches done to elaborate on the problems of English training market and some attempts to provide some solutions. Peng Hongbing(2007), Cao Hua'e(2008), and Chen Hongguang (2008) pointed out the low market entry access and false advertising being the core problems. Through a comparison between English classes of middle school and that of training institutions, Chen Lei (2016) summarized the differences in teaching focus, method and advantages of each Marina Falasca (2011) explored the main barriers to adult learning discussed in the literature. 
The characteristics of adult English education varied in different people's views. Xu Zhen(2015) expounded the adult English education characterized by low market entry barriers, low cost, yet a considerable financial profit. Wang Shuai(2019) flagged up the professional training modes, and specialized curriculum, teaching management and standardized testing system as the core.

Teaching methods were also studied to explore effective ways in adult English training. Communicative language teaching has been on the tear in the English teaching organizations in Shenzhen(Xu Rong, 2006). Peter Jarvis(2012) echoed the idea of communicative approach and put forward a model of adult learning. Xu Guohui(2009)integrated the researches in ecology of education. NiuWeihong(2013) and Jing Xiaoyan(2015) investigated into practical English Grammar teaching.

Online learning has been hailed by many people. Sun wei and Cui gang(2007) studied how the project CUTE2(Chinese University Teacher Training in English) manage to effectively implement the adult English training for university teachers by applying the use of E-learning. Anne A. Ghost Bear(2012) argued that adult learners use a unique combination of skills and strategies to seize the opportunities presented by Information Revolution at hand. Wang Meixia(2015) viewed mobile learning as the trend of modern English learning. Furthermore, Cai Xiaolin, Pan Lina(2017) spotted on micro media and the means of online English training. Guo Ying(2017) hold the idea that Internet plus can serve to information sharing and perfect the traditional teaching modes. Zhang Fang(2017) commended the supremacy of the learning English against the backdrop of Internet plus.

\subsection{Practice Background}

Few researchers managed to pinpoint the problems by taking the reality of learners' residence into account. Though Jenifer and Vanek(2015) pointed out the misalignment between the policy in the US and Liu Yating(2010), Hu Peng(2015) and Zhou zhouyan(2015) respectively took Ganzhou, Jiangxi province; Changsha, Hunan Province; and Ningbo, Zhejiang province as examples, these surveys all took place in large cities with relatively high economic growth and a more mature training market.

Though adult English training is burgeoning, studies on specific cases are rare, not to mention one featuring on cities with Free Trade Area identity. With regard to the Free Trade Area, the training modes should be more effective and applicable to every citizen in those cities.

With a host of studies on overall problems in the adult English training or teaching methods employed in adult English, training class abounded, but few put forward updated solutions.

\section{RESEARCH PROCESS}

This study gave out questionnaires to Zhoushan and Xi'an to give some solutions which can smooth the targeted adult training modes in Free Trade Areas and meanwhile be applied universally to adult English training.

The study used questionnaires pertinent to the status quo of adult English training in Xi'an and Zhoushan along with SPSS to analyze the data gathered in the questionnaires.

"In an era of breathtaking change, it is impossible to acquire early in life the knowledge that adulthood will require." (Knowles, 1998) In the same vein, all the people partaking in this questionnaire are adults. Their ages range from 18 to 60 and above, of which 97 respondents fall into the range of age $18-30$, which account for $32.33 \%$, people from age $31-45$ register $48 \%$ while 56 people between age $46-60$ occupy $18.67 \%$ and the rest( 3 respondents) above 60 only number a mere $1 \%$. With respect to their education background, 5\% respondents had junior high school level and below, $13 \%$ of them went to junior college or high school while the large proportion $(51.33 \%)$ of respondents had a college degree, and the rest 92 people, accounting for $30.67 \%$, had a graduate degree. Among the 300 respondents in these questionnaires, the number of respondents from Xi'an and Zhoushan was equal. 300 questionnaires were given out and retrieved in SO JUMP, a professional online platform dealing with questionnaire survey.

The data of the questionnaires were analyzed by SPSS so as to ascertain the correlation between many variants and identify the problems so as to offer some solutions.

The findings are categorized into 3 parts: First, people's views on adult English learning along with their experiences. Second, the status quo of adult English training organizations and their conundrums. Third, what can be done to improve present training modes. 


\section{FINDINGS}

\subsection{Attitudes towards Adult English Training}

Figure1. Basic Information and Views of Respondents

\begin{tabular}{|l|l|l|l|l|}
\hline & $\begin{array}{c}\text { City of } \\
\text { Residence }\end{array}$ & Age & $\begin{array}{c}\text { Education } \\
\text { Background }\end{array}$ & $\begin{array}{c}\text { Experience of Learning English } \\
\text { in Training Organizations }\end{array}$ \\
\hline English learning is important & 0.057 & -0.55 & -0.05 & 0.005 \\
\hline Illiteracy of English & -0.038 & $0.226^{* *}$ & $-0.280^{* *}$ & -0.057 \\
\hline Basic conversions only & 0.006 & $-0.237^{* *}$ & -0.073 & -0.042 \\
\hline Have the experience of learning & $-0.261^{* *}$ & 0.14 & $-0.305^{* *}$ & -0.046 \\
\hline Communicate freely with others & 0.13 & $-0.304^{* *}$ & 0.064 & 0.024 \\
\hline Master professional knowledge & $0.320^{* *}$ & 0.104 & $0.520^{* *}$ & 0.076 \\
\hline
\end{tabular}

$* \mathrm{p}<0.05 * * \mathrm{p}<0.01$

Chart 1 mainly manifests the correlation between individuals and the adult English training. The city of residence, your age as well as education background have the correlation coefficient of 0.057, 0.055 and -0.050 respectively and thus doesn't reach statistical significance, indicating that there exists no correlation between your views on the significance of adult English learning and the above mentioned 3 variants. Adult English education, by the same token, have its pervasiveness. Whether people dwell in coastal area(Zhoushan) or inland area(Xi'an); ill-educated or well-educated; in their 20 s or even in their 60 s, most of them(74.33\%) share the same view that adult English learning is significant to enlarge their knowledge reserve. Though $20.67 \%$ of the respondents believed that Artificial Intelligence and machine translation are gathering momentum, especially the former has upended many industries so much so that they glossed over the importance.

However, adult English learning is by no means replaced by them since the learning process enhance the communication skills of people and bridge the gap of cultural differences. Also, most people would dub English learning consumption as a developmental one. Still, 5\% participants believed that adult English learning had nothing to do with their lives, despite the small percentage, it will bring about a negative impact on society as a whole and hinder the development of adult English education.

In addition, the figures in the chart 1 showcases the relationship between your English level and your age as well as education background. The age registers a significant positive correlation with "have not learn English before and do not know a bit of English" and a negative correlation with "able to conduct basic conversations", "have learned English systematically and "feel free to communicate with others". Besides, there being no correlation between your age and "have once learned English but much of the knowledge was forgotten", which illustrates that generally as people grow older, their English ability diminishes. But the age does not necessarily exert negative influence on your English learning, it is the efforts you made in the English learning make a difference. If you once started to learn English and kept it as a daily routine, then you will reap harvest and vice versa.

When it comes to the education background, the well-educated tend to outshine the others, and will be more likely to have higher language proficiency which enables them to work in related industries. In a reverse, some well-educated who merely use English were also left behind and do not have the grasp of basic conversations. From the fact that education background cannot guarantee English proficiency unless you persist in learning English, therefore, the initiative of learning is self-evident.

Not surprisingly, there being no distinct correlation between your present English level and your experiences of signing up for an English training organization since in the analysis of chart 1, we just drew the conclusion of the importance of initiative learning. Besides, the learning opportunities themselves cannot be translated into knowledge directly. The presence of those extracurricular activities has nothing to do with whether you view it as important or not but it will obviously influence your participation in them or not. That is to say, your English level does not vary with the external factors but mainly lie in yourself. Now that the focus of adult English learning is the learner, we should develop adult English training modes as learner-centered and give full scope to learners' motivation.

\subsection{The Status Quo of Adult English Training}

Figuring out the status quo is an effective way to seek a plan in an all-round way. Your city of residence was significantly and positively correlated with "non-existence" and "there are only few 
organizations and only open to some limited training objectives". Yet, there is negative correlation between the city of residence and "the large number of adult English training organizations". We can sum up some conclusions drawing upon the relations below. Most residents in Zhoushan chose "nonexistence" (15.67\%) and "there are only few organizations and only open to some limited training objectives" $(50.33 \%)$. The training organizations in Xi'an outnumber those in Zhoushan, which may accrue to its position as a provincial capital which abounds in an array of colleges. In the same vein, students have more demand for learning organizations. Further, the Belt and Road Initiative has galvanized the opportunities, so Xi'an do enjoy a vantage point. Then, we move on to the problems triggered by the poor number of training organizations in Zhoushan, which directly lead to the failure of learners' participation in training institutions. The motivation of adult learners in Zhoushan was largely constrained by the limited number and implicit training objectives. In the meantime, their learning objectives will not be attained in the poor academic atmosphere. Though training organizations cannot directly improve the English level of learners, but the diversified training courses will contribute to learners participated.

Figure2. The Status Quo of Training Organizations

\begin{tabular}{|l|l|l|l|l|l|l|}
\hline & $\begin{array}{l}\text { Non- } \\
\text { existence }\end{array}$ & $\begin{array}{l}\text { Percenta } \\
\text { ge }\end{array}$ & $\begin{array}{l}\text { Few Organizatio } \\
\text { ns and limited } \\
\text { courses }\end{array}$ & $\begin{array}{l}\text { Percent } \\
\text { age }\end{array}$ & $\begin{array}{l}\text { Many } \\
\text { organizations }\end{array}$ & $\begin{array}{l}\text { Percenta } \\
\text { ge }\end{array}$ \\
\hline City of residence & $0.214 * *$ & $15.67 \%$ & $0.180^{* *}$ & $50.33 \%$ & $-0.297 * *$ & $35.67 \%$ \\
\hline $\begin{array}{l}\text { Experience of learni } \\
\text { ng English in train } \\
\text { ing organizations }\end{array}$ & $-0.181 * *$ & & $-0.171 * *$ & & $0.280 * *$ \\
\hline
\end{tabular}

$* \mathrm{P}<0.05 * * \mathrm{P}<0.01$

Figure3. People's View on Online Education

\begin{tabular}{|l|l|l|l|l|}
\hline & $\begin{array}{c}\text { Good } \\
\text { Choice }\end{array}$ & $\begin{array}{c}\text { Money- } \\
\text { saving }\end{array}$ & $\begin{array}{c}\text { Convenient } \\
\text { to Review }\end{array}$ & $\begin{array}{c}\text { Inconvenient for Teacher- } \\
\text { student Interactions }\end{array}$ \\
\hline WeChat articles & 0.216 & 0.075 & 0.146 & -0.117 \\
\hline Online courses & 0.123 & $0.225^{* *}$ & $0.175^{* *}$ & 0.106 \\
\hline One-on-one foreign teachers' courses & -0.023 & $0.175^{* *}$ & 0.025 & 0.121 \\
\hline Other methods & 0.007 & 0.084 & 0.125 & 0.156 \\
\hline Credibility of courses have no guarantee & 0.035 & 0.093 & 0.106 & 0.038 \\
\hline Learning material is not well-selected & 0.087 & $0.273^{* *}$ & 0.126 & 0.024 \\
\hline Not systematic & 0.009 & $0.207^{* *}$ & $0.249^{* *}$ & $0.262^{* *}$ \\
\hline Lack the learning atmosphere & -0.026 & 0.143 & $0.205^{* *}$ & $0.255^{* *}$ \\
\hline
\end{tabular}

$* \mathrm{P}<0.05 * * \mathrm{P}<0.01$

Given the pervasive smartphones, access to Internet and booming gig economy, online education sprung up like mushroom. Online learning: E- learning. Fast, cheap, and good(George M. Piskurich $\mathrm{PhD}, 2010)$. What needs mentioning is that there is not any correlation between "the convenience of time and place" and "online education is an effective way". People give prominence to the improvement online training brings about rather than mere convenience. What's more, people who view adult English education practical tend to consider the courses setting up by colleges and one-onone video lessons of foreign teachers a feasible practice, which is clearly more expensive than other types of class but win more favor of people. This demonstrates that people value the results of the course rather than simply pursuing a cheap way of learning. Moreover, MOOCs (Massive Open Online Courses), like iCourse, a Chinese learning website, Coursera and the like are highly praised in that learners believe that they are more authoritative than others. The correlation cannot be found between "the inconvenience of communicating with teachers" and "the online education is a practical teaching mode". As a matter of fact, teachers have already tapped into the convenience presented by online courses as well as mobile devices, and chat groups are ubiquitous in classes, which in most cases facilitate the problem-solving and instant communication.

\subsection{Ways to Facilitate the Adult English Training}

To understand the reasons why people are not organization-goers and figure out their learning motivations as well as the direct opinions they named can be conducive to solving this problem. The reason why people do not resort to training organizations mainly lies in the lack of time(52.67\%) and 
they find going to training institutions taxing(30.67\%). Adult learners, different from students in school, have already stepped out of the harbor of their families and become breadwinners so that they will take financial factors into consideration(21.33\%). Time was also included for mainly two reasons: First, they need to spend time taking care of family members; Second, they are deliberate on the opportunity cost of the time spent in training organizations, which could yield a considerable economic income.

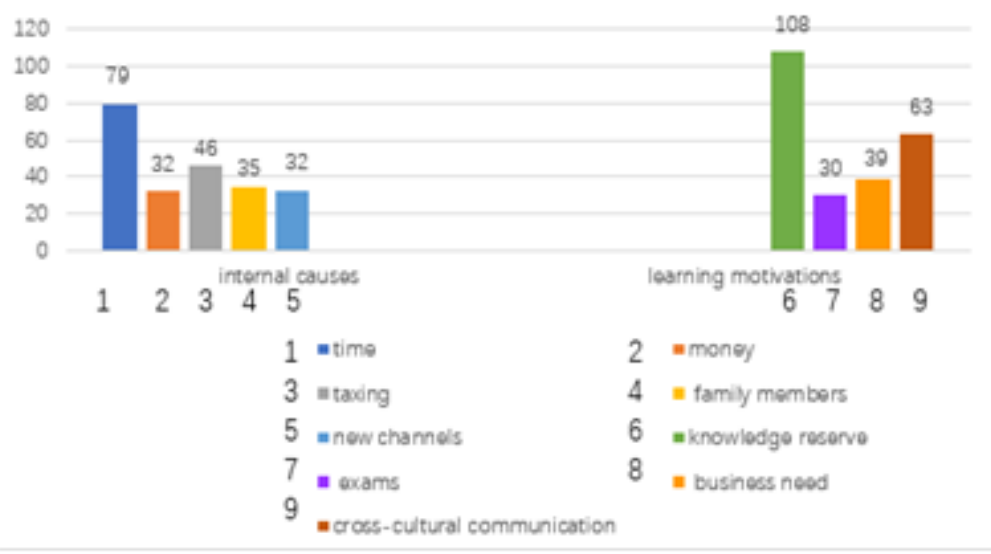

Figure4. Indices of Learners' Motivation and Internal Causes

In terms of learning motivation, to enhance their own education level takes the lead accounting for $72 \%$, and second to it is to promote cross-cultural communication ability (42\%). Then $33.67 \%$ participants explained that they go to adult training organizations aiming to fulfill the business needs of their companies. Besides, $19 \%$ respondents said that their motivation is to pass exams such us IELTS, TOFEL and the like. Adults are always target-oriented and most adults embark on English learning with specific goals in their mind. Training organizations should take the learners' motivation into account from the outset of course setting.

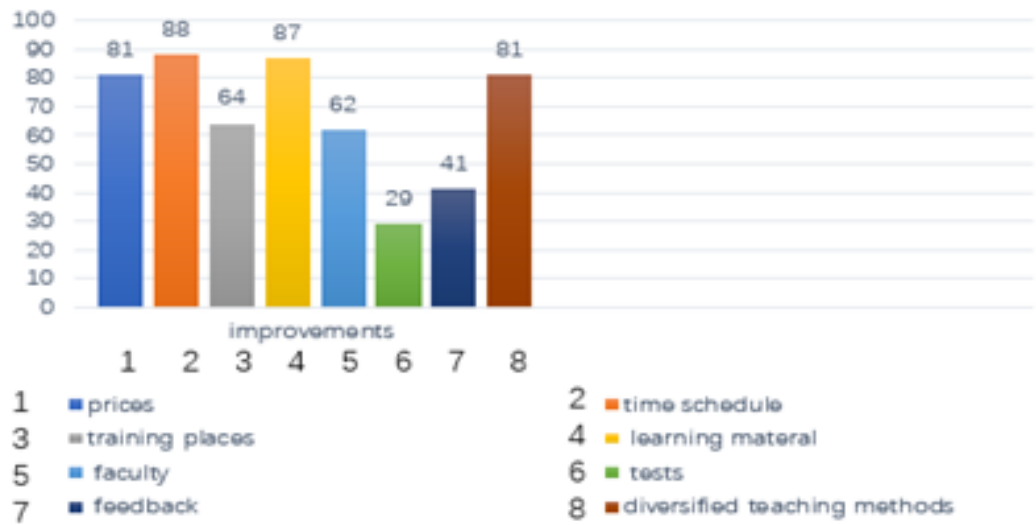

Figure5. Improvements to the Online Training Mode

When asked what can we do to improve the status quo of the adult English training, participants believed a more feasible price and a considerate timetable should be put in place. Therefore, online English education emerged at the right time. Though it can save time and money, it comes with some flaws naturally which merit our attention and improvement.

As "We Media" has gone viral on the Internet, coupled with anonymity online, people may question the credibility of articles posted on WeChat. One-on-one foreign teachers' video lessons gain its popularity because it correlates with flexible training place, professional competent faculty, a kaleidoscope of teaching methods and satisfaction of personal needs. "joining the online courses presented by colleges" has positive correlation with "the price should be affordable" (54\%), "the faculty should be professional" (41.36\%), "the quizzes should be made a routine to learners in English training organizations" (19.33\%), "learning feedback should be delivered to learners" $(27.33 \%)$ and "the teaching modes should be personal and diversified" (54\%). These suggestions altogether pose open questions like regulating affordable prices, raising the bar for cultivating professional faculty, 
across-the-board teaching evaluation and feedback, along with reliable teaching methods of teachers and a customized learning syllabus.

\subsubsection{Customized Course Setting}

People are the participants of training activity, therefore the crux of establishing training modes with remarkable achievements lie in people themselves.

From the onset of English training, people involved should carry an earnest attitude towards English itself. 4\% respondents do not even think English has something to do with them, to whom all kinds of training modes are futile. To elicit the learners' interests and keep it alive is of paramount importance.

Training institutions cannot just churn out syllabuses which once proved feasible to others or even does not have syllabuses at all. Adult English training should be learner-oriented, given the characteristics of adult English learners, that is, the varied age difference and language proficiency, unassured studying time and clear goals in learning(Zhou zhouyan, 2010), thus the organizations should customize learning schedules, places, timetables and teaching courses geared to the needs of learners.

\subsubsection{Differentiated Coverage of Courses}

Most adult learners have specific goals, the existing training modes cannot act in line with them. Many Participants from Zhoushan in the questionnaires noted that the existing organizations were only open to some training objectives, which were chalked up to the scarcity of the type of courses. The training didn't give full scope to vocational English, and usually narrow down its definition to business English. (Shi Xiaowei, 2008). Not all the learners aspire for knowledge in business English, some according to the questionnaires, they just want to enhance their education or merely want to master some essential cross-cultural communication skills to keep abreast of times. Thus, the monotonous outdated lessons absolutely cannot act in line with their objectives. Before launching new courses, organizations should tap into market segmentation to serve niche markets.

The vague divided stage of courses should be avoided. In many circumstances, a book proves to be a piece of cake may be obscure to another. I recommend some tests or simple talks to better grasp the basic information of learners before the inception of the classes. And the textbooks chosen should be of great consistency.

The difficulty setting of the teaching syllabus should also be underpinned by scientific teaching methods. The Zone of Proximal Development (ZPD) is "the distance between the actual developmental level as determined by independent problem solving and the level of potential develop ment as determined through problem-solving under adult guidance, or in collaboration with more capable peers." (Vygotsky, 1978). Later, comprehensible input (Krashen, 1982) also known as "i+1" echoed ZPD, in which " $\mathrm{i}$ stands for the current level of the learner, 1 means the learning material should be a little bit higher than the present level". The two theories altogether shed light on what kind of goal is attainable for the learners, that is a bit higher than the present level of the learner. Thus, when adult training organizations or online training websites chooses their textbooks, they should carry out the above-mentioned rule for difficulty setting.

\subsubsection{The Improvement of Teaching Modes}

With regard to teaching modes, the much-hyped heuristic learning is a truism but it may have different connotations at present. Something new can be done to the banal classrooms. By applying flipped classroom, learners can truly participate in the class. Learning being "the process whereby knowledge is created through the transformation of experience" (Kolb,1984). The knowledge teacher imparted to the learners is indirect knowledge and it is easy to forget, unless combined with learners' hands-on experience. Besides the form of the class, special-designed classroom arrangements can also help. Rather than sitting in a line as usual, the seats forming a circle so that they can discuss freely and without reserve. Also, the number of people in the class should be limited to 20 utmost to guarantee the classroom efficiency and make sure everyone is engaged in class.

A complete teaching design should also embrace teaching evaluation and feedbacks as well. Though an adult learning environment is one in which students do have some freedom and autonomy (McGregor\&Ryan, 2011). Yet adult English learning is by no means unplanned. Teaching evaluation here does not necessarily be synonymous with quizzes, dictations, etc. Teachers can also conduct a process evaluation to appraise academic achievements of learners, which can nudge students into learning rather than cramming. As such, students are also motivated to learn instead of studying for tests. 


\subsubsection{Internet-assisted Learning Mode}

Internet plus can serve to information sharing and perfect the traditional teaching modes as well as broaden the ways of learning. (Guo Ying, 2017) Now that nearly everyone has been addicted to their mobile phones, many businessmen are beginning to tap into this opportunity. Online courses have been on a tear in recent years, characterizing of low payment and convenient to playback and review along without the restriction of time and space. A pool of social media and apps have developed their learning columns. Educational media established their own apps and are launching their online classes, apps featuring E-dictionary like Youdao followed suit, much less some dubbing, listening apps. At present, people are bombarded by information everyday so much so that have no clues to find a starting point.

Many people are already aware of the disadvantages of lacking feasible organizational forms, systematic teaching syllabus as well as enabling learning atmosphere in the class, which altogether positively related to "it is convenient to review and playback". According to Figure 3, the inconvenience of communicating with teachers has positive correlation with the improper organizational form and the scarcity of systematic syllabus and learning atmosphere. In this way, we can accord these problems to the absence of communication.

Online courses making accessibility easier is disadvantageous in communicating with their user group since many procedures underwent in the brick-and-mortar training organizations are now delivered to the websites, many of which are run by the third-party platforms, so it is hard to guarantee effective dialogues. Ways to solve the problem of inefficient communication also lie in mobile devices. The traditional classroom teaching is commended for its learning atmosphere, where communicative language teaching methods are widely applied. Communication here can be subdivided into 2 kinds. One is the communication between all learners, the other is teacher-student interaction. With regard to the former, loads of group works, like presentation, drama plays, role plays greatly galvanize learners' interest and impress them greatly. The interactivity can also be achieved by adding discussion boards on the websites, chat rooms, etc. As for the latter, considering the fact that live-streaming classes have created a buzz on the Internet, we can tap into the its timeliness and serve for interaction between teacher and learner. Another way is to foster a respectful relationship in classroom teaching. An equal relationship is of great significance. According to Affective Filter Hypothesis(Krashen,1985), the learners' attitudes towards teachers make a difference. That is to say, a good relationship between learners and teachers matters. The inability to communicate with teachers online can be remedied with distinctive teaching modes teachers have. Either a humorous tone, relaxing atmosphere, well-arranged content, or some logical thinking is preferable.

\subsubsection{Brand-effect to Counter Bad Teaching Quality}

In the running-up to online courses, adult English learners now frown upon the quality of information online and worried about teacher's ability so that they meticulously choose those courses presented by colleges according to questionnaires. Brand effect here is the only guarantee to the quality. When people are calling for something authoritative, the Ministry of Education should publish standards to all the online courses and competent department should have them screened to make sure its authenticity. In the same vein, standards are also needed in those brick-and-mortar training organizations to enhance the market access. Moreover, the asymmetry of information leads to people's worrying about teacher's ability. If all the online training can increase their transparency, that is, by displaying their certificates, then many problems will be solved.

\subsubsection{Groupon Can Satisfy Quality and Price}

As the quality increases, the price fuels. In terms of the pricy courses which do have a good effect, like the courses promoted by colleges and one-on-one lessons of foreign teachers. People can purchase those by the means of group-buying to save money. Groupon achieves a win-win scenario since it makes great use of information sharing and serves both as an economical way for the consumer and a method for the seller to achieve scale interests through volume discounts.

\section{CONClusion}

The adult English training stemming from the need of people will continually gather pace in Free Trade Areas and beyond. Keeping with the wheels of history, the training modes in the future will be mainly focused on online training, complemented by brick-and-mortar training organizations. Though 
the people's attitude towards English learning is upbeat and the development is on the track, the status quo of adult training organizations remains disappointing in that the scarcity of training organizations and meager class setting to some extent constraint the adults participating in it.

According to the characteristics of adult English training and its differences from that of high schoolers' English training or learning in school, along with the internet plus, the study proffers a host of solutions geared to the need of adults.

However, this survey is merely a tentative attempt in studying adult English training, and data gathered by questionnaires may err sometimes, for respondents may have ambiguous varied standards in the questions and may sugarcoat the truth. Besides, there is no panacea to problems of adult English learning, the training modes work for one person may fail the other.

With an eye for lifelong study and sustainable development of people, it is beyond doubt that adult English training will serve as the new growth drivers in the decades to come.

\section{REFERENCES}

[1] Bear, A. A. G. (2012). Technology, Learning, and Individual Differences. Journal of Adult Education, 41(8), 27-42.

[2] Jarvis, P. (1987).Adult Learning in the Social Context. New York: Croom Helm.

[3] Krashen, S. (1982). Principles and Practice in Second Language Acquisition. Oxford etc: Pergamon Press.

[4] Knowles, M. S., Holton, E. F. III, Swanson, R. A. (1998). The Adult Learner. Huston, TX: Gulf.

[5] Krashen, S. (1985). The Input Hypothesis: Issues and Implications. London, UK: Longman Publishing Press.

[6] Piskurich, G. M. (2010). Online Learning: E-Learning. Fast, Cheap, and Good. Performance Improvement, 45(1), 18-24.

[7] Kolb, D. 1984. Experimental Learning. Englewood Cliffs: Prentice Hall Inc.

[8] Vygotsky, L. S. (1986). Thought and Language. Cambridge, MA: MIT Press

[9] 文秋芳. (2001). 英语学习者动机、观念、策略的变化规律与特点. 外语教学与研究, 33(2), 105-110.

[10] 王欣, 戴炜栋. (2015). 基于“二语动机自我系统”理论的二语动机策略实证研究. 外语教学, 36(6), 4852 .

\section{AUTHORS' BIOGRAPHY}

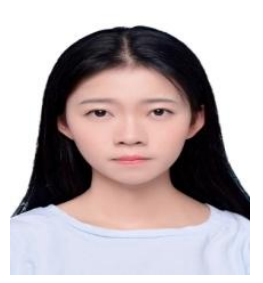

Zixin Wang was born in Xi'an, China in 1997. She is a third-year English major in Zhejiang Ocean University.

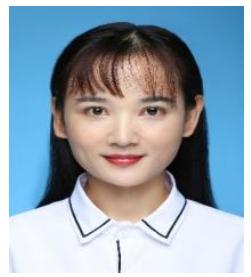

Xiaoxu Chen was born in Zhoushan, China in 1986. She received her M.A. degree in English language and literature in Shanghai International Studies University, China. She is an lecturer in the School of Foreign Languages, Zhejiang Ocean University, China. Her current researches focus on British and American culture.

Citation: Zixin Wang, Xiaoxu Chen. "A Study on Adult English Training Modes under the backdrop of Free Trade Areas." International Journal of Humanities Social Sciences and Education (IJHSSE), vol 6, no. 3, 2019, pp. 61-67. doi: http://dx.doi.org/10.204 31/2349-0381.0603008.

Copyright: (c) 2019 Authors. This is an open-access article distributed under the terms of the Creative Commons Attribution License, which permits unrestricted use, distribution, and reproduction in any medium, provided the original author and source are credited. 